\title{
PENINGKATAN KEUNGGULAN KOMPETITIF PADA UMKM GERABAH MELALUI MODEL E-BUSINESS
}

\author{
Tutik Khotimah \\ Dosen Fakultas Teknik, Program Studi Teknik Informatika \\ Universitas Muria Kudus \\ Email: tutik.khotimah@gmail.com \\ Rina Fiati \\ Dosen Fakultas Teknik, Program Studi Teknik Informatika \\ Universitas Muria Kudus \\ Email: rfiati003@yahoo.com
}

\begin{abstract}
ABSTRAK
Industri kerajinan gerabah Mayong adalah industri rumahan yang patut dilestarikan. Untuk menjaga keberlangsungan industri tersebut, pemanfaatan internet sebagai media promosi dan proses transaksi bisnis menjadi solusi yang menarik. Penelitian ini mengangkat permasalahan bagaimana meningkatan keunggulan kompetitif pada UMKM gerabah melalui model $e$-business. Tujuannya adalah untuk menghasilkan model $e$-business yang dapat digunakan untuk meningkatan keunggulan kompetitif. Manfaat yang diharapkan dengan model ini adalah UMKM gerabah dapat mempromosikan produknya melalui internet. Selain itu, proses jual beli dapat dilakukan pula melalui internet.
\end{abstract}

Kata kunci: e-bisnis, gerabah.

\section{ABSTRACT}

Pottery industry in Mayong is a cottage industry that should be preserved. To sustain the industry, the use of the Internet as a promotional medium and process business transactions become an attractive solution. This study raised the issue of how to improve the competitive advantage on UMKM of pottery through e-business models. The goal is to generate e-business models that can be used to improve competitive advantage. The expected benefits to this model is the UMKM pottery can promote their products through the internet. In addition, the process of buying and selling can be done also through the internet.

Keywords: e-business, pottery industry.

\section{PENDAHULUAN}

\subsection{Latar Belakang Masalah}

Perkembangan teknologi komunikasi dan informasi tidak hanya berpengaruh terhadap kecanggihan teknologi itu sendiri, tetapi juga berpengaruh terhadap gaya hidup dan jumlah konsumsi manusia terhadap teknologi tersebut. Kebutuhan manusia akan akses informasi melalui internet, intranet, atau ekstranet semakin meningkat, diimbangi dengan teknologi search engine yang semakin canggih. Hal ini juga menyebabkan terjadinya peningkatan terhadap kecepatan perubahan. Pertumbuhan yang cepat dan adanya adopsi teknologi baru telah memberikan fasilitas terhadap perubahan organisasi [14]. Kemajuan terbaru dalam teknologi komunikasi dan informasi, serta penurunan secara cepat dalam hal biaya komputasi dan komunikasi, telah memungkinkan pengembangan cara-cara baru untuk menciptakan dan memberikan nilai, yang telah menawarkan ruang lingkup untuk penciptaan mekanisme pertukaran dan arsitektur transaksi secara tidak konvensional [1] dan menekankan kemungkinan untuk desain baru mencakup batas bentuk-bentuk organisasi [3][5].

Kegiatan dunia usaha menggunakan teknologi internet adalah cara yang inovatif dalam melakukan kegiatan perusahaan untuk memasuki pasar di dunia maya yang disebut sebagai electronic business (e-business) dan electronic commerce (e-commerce) [12]. Dengan memanfaatkan teknologi internet, perusahaan dapat melakukan berbagai kegiatan bisnis secara elektronik seperti; transaksi bisnis, operasi fungsi-fungsi perusahaan, berbagi informasi dengan konsumen dan suplier untuk mempertahankan hubungan sebelum, selama dan setelah proses pembelian [8][16].

Pada umumnya fitur situs perusahaan dilengkapi dengan fungsi-fungsi informasi, pemesanan atau penjualan, pembayaran, pelayanan konsumen dan komunikasi [6][11][13][15] sehingga dengan menggunakan situs perusahaan, si pengakses (users) akan merasakan berbagai manfaat (usefulness) dalam menjelajah situs perusahaan tersebut. Manfaat menggunakan situs perusahaan bagi para pengakses antara lain: mempercepat dan mempermudah pencarian informasi tentang barang dan jasa [7] atau dapat meningkatkan produktivitas dan efektivitas kerja [9].

Gerabah merupakan perkakas yang terbuat dari tanah liat yang dibentuk, dikeringkan, kemudian dibakar sehingga dapat digunakan sebagai alat-alat yang berguna untuk membantu kehidupan manusia. Contoh gerabah antara lain: kendi (tempat air minum) dalam berbagai bentuk dan variasi, kendil (tempat menaruh ari-ari, dapat juga digunakan untuk tempat meracik jamu), celengan dalam berbagai variasi, pot, guci, remitan (miniatur perabot rumah tangga yang digunakan untuk mainan anak-anak) dan sebagainya. 
Daerah Mayong kabupaten Jepara adalah salah satu daerah yang menghasilkan gerabah di Indonesia [10]. Industri kerajinan gerabah merupakan industri rumahan yang dikelola oleh masyarakat Mayong sebagai mata pencaharian. Meski pun sebagai industri kecil, permintaan konsumen terhadap gerabah termasuk tinggi. Bahkan permintaan tersebut sering kali tidak terpenuhi, apa lagi ketika terdapat event seperti Dandangan, Sekatenan, Besaran, dan sebagainya. Pemasaran produk gerabah dilakukan dengan berbagai cara, mulai dari mendasarkan barang dagangan di pasar-pasar atau pada acara-acara ritual, dapat juga dilakukan dengan berkeliling menjual produk-produk gerabah dengan menggunakan sepeda motor atau berjalan kaki dengan memanggul keranjang berisi gerabah. Namun, ada juga pembeli yang datang ke rumah-rumah, baik pembeli tersebut bertindak sebagai distributor mau pun sebagai konsumen langsung. Produk-produk dari kerajinan gerabah Mayong dipasarkan ke berbagai daerah seperti Kudus, Demak, Semarang, Solo dan daerah sekitarnya.

Pemanfaatan teknologi internet sebagai media untuk meningkatkan keunggulan kompetitif UMKM gerabah merupakan solusi yang menarik. Selain digunakan untuk promosi, penjualan barang dapat dilakukan melalui internet sehingga dapat meningkatkan produktivitas dan efektivitas kerja. Untuk itu, permasalahan yang diangkat dalam penelitian ini adalah bagaimana meningkatan keunggulan kompetitif pada UMKM gerabah melalui model $e$-business.

\subsection{Tujuan}

Tujuan dari penelitian ini adalah untuk menghasilkan model $e$-business yang dapat digunakan untuk meningkatan keunggulan kompetitif pada UMKM gerabah.

\subsection{Manfaat}

Hasil penelitian ini diharapkan dapat memberikan kontribusi terhadap UMKM gerabah dalam meningkatan keunggulan kompetitif, baik dalam hal promosi mau pun dalam kegiatan jual beli. Dengan model e-business, UMKM gerabah dapat mempromosikan produknya melalui internet. Selain itu, melalui internet pula, proses jual beli dapat dilaksanakan sehingga dapat meningkatkan keunggulan kompetitif.

\section{TINJAUAN PUSTAKA}

\subsection{E-Business}

Electronic business (e-business) [2] adalah penggunaan internet untuk jaringan dan memberdayakan proses bisnis, perdagangan elektronik, komunikasi organisasi dan kolaborasi dalam perusahaan dan dengan pelanggan, pemasok, dan pemangku kepentingan lainnya. E-bisnis memanfaatkan internet, intranet, extranet dan jaringan lain untuk mendukung proses komersial mereka. Sedangkan electronic commerce (e-commerce) adalah pembelian dan penjualan, pemasaran dan pelayanan produk dan jasa melalui jaringan komputer.

\subsection{Industri Kerajinan Gerabah}

Industri kerajinan gerabah adalah industri yang berbahan baku tanah liat dengan proses produksi menjadi gerabah [4]. Gerabah adalah perkakas yang terbuat dari tanah liat yang dibentuk kemudian dibakar agar dapat digunakan sebagai alat-alat yang berguna untuk membantu kehidupan manusia. Beberapa produk yang dihasilkan dari kerajinan gerabah di daerah Mayong antara lain: kendi (tempat air minum) dalam berbagai bentuk dan variasi, kendil (tempat menaruh ari-ari, dapat juga digunakan untuk tempat meracik jamu), celengan dalam berbagai variasi, pot, guci, remitan (miniatur perabot rumah tangga yang digunakan untuk mainan anakanak) dsb [10].

\section{METODE PENELITIAN}

\subsection{Metode Pengumpulan Data}

Dalam pengumpulan data, metode yang digunakan antara lain:

1. Studi literatur

Studi literatur dilakukan dengan mempelajari bahan-bahan tertulis baik yang berasal dari buku, jurnal, atau artikel-artikel yang ada di internet sesuai dengan masalah yang berkaitan.

2. Wawancara dan Observasi

Pada metode ini peneliti mencari dan mengumpulkan data-data yang ada relevansinya dengan judul penelitian ini pada pihak terkait yaitu UMKM gerabah yang ada di daerah Mayong kabupaten Jepara.

\subsection{Perancangan Sistem}

Untuk merancang sistem, pemodelan yang digunakan adalah Unified Modelling Language (UML). Ada pun diagram yang digunakan yaitu Use Case Diagram dan Statechart Diagram. 


\section{PEMBAHASAN}

\subsection{Gambaran Penjualan Kerajinan Gerabah}

Beberapa industri kerajinan gerabah di daerah Mayong memasarkan sendiri produk yang dihasilkan dalam event seperti Dandangan, Sekatenan, Besaran, dsb. Ada juga yang menyetorkannya kepada pihak distributor atau konsumen langsung. Gambar 1 berikut ini menjelaskan alur kegiatan penjualan dalam industri kerajinan gerabah di daerah Mayong

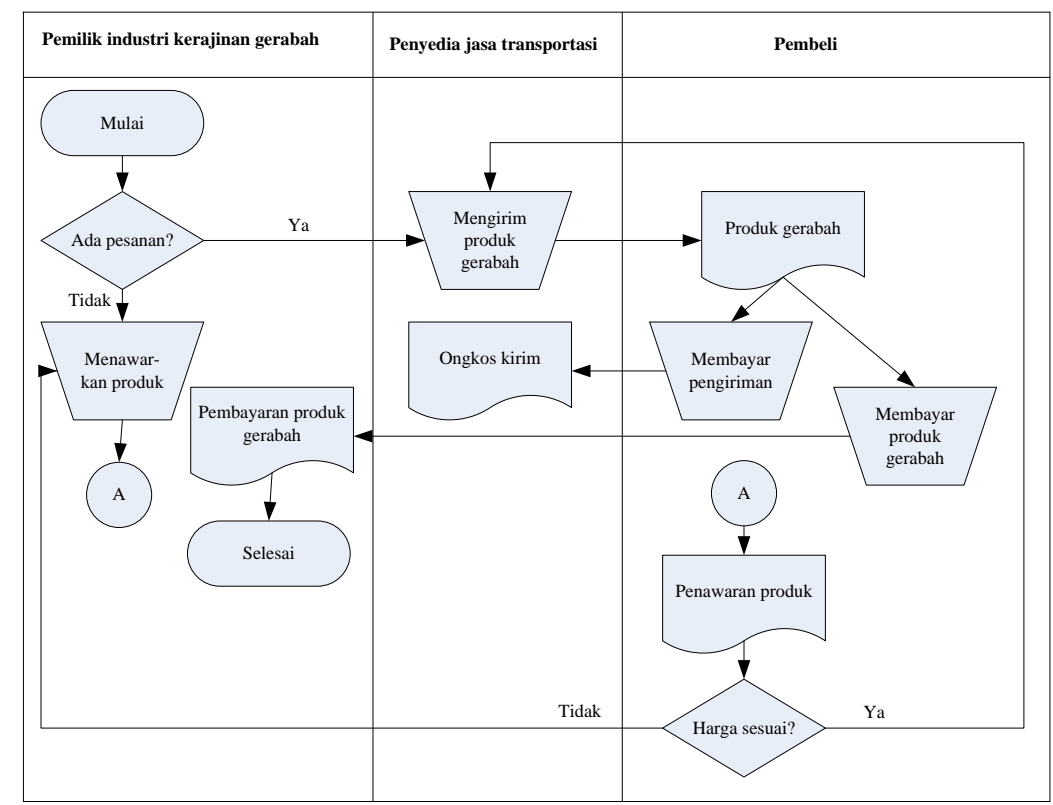

Gambar 1 Alur Penjualan Kerajinan Gerabah [10]

\subsection{Model E-Business Industri Kerajinan Gerabah}

Model e-business industri kerajinan gerabah daerah Mayong kabupaten Jepara dapat digambarkan seperti pada gambar 2 berikut:

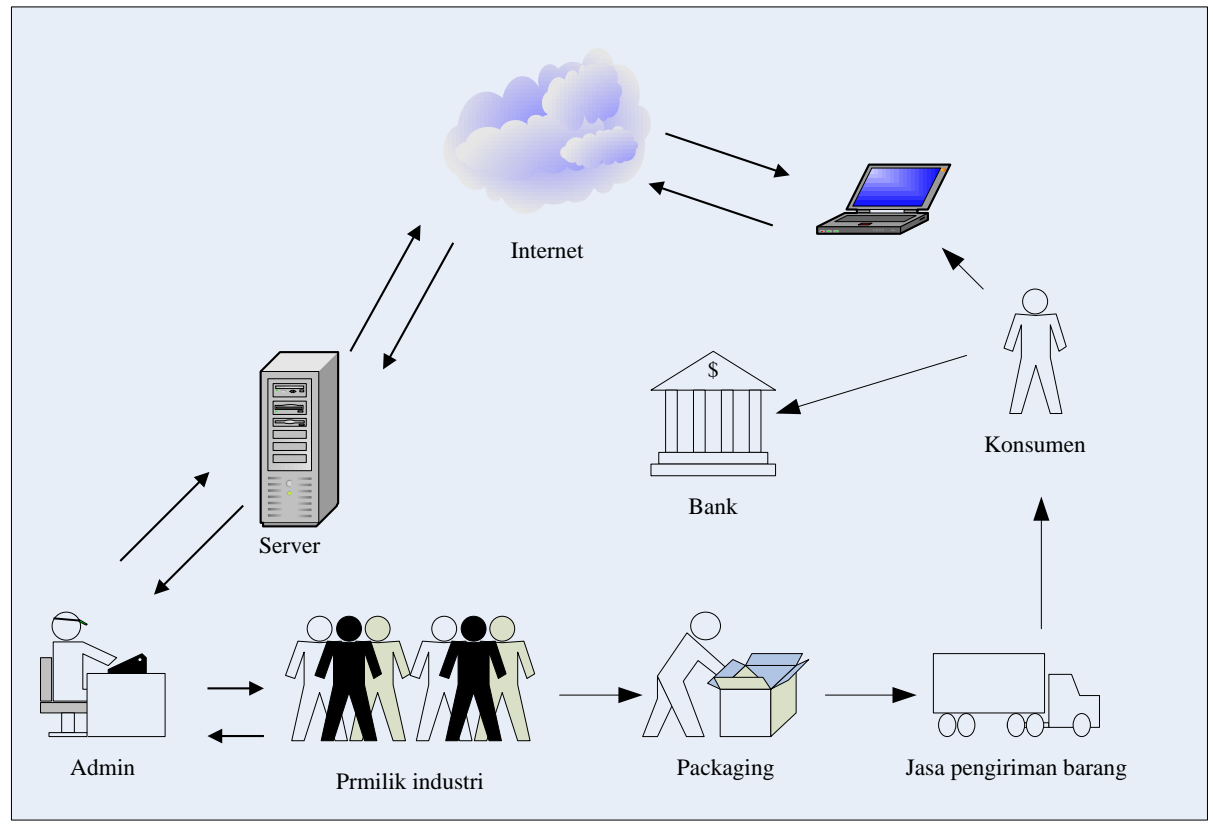

Gambar 2 Model E-Business Industri Kerajinan Gerabah [10]

Dalam model $e$-business ini, ada 2 proses bisnis yang ditangani, yaitu proses bisnis internal (berhubungan dengan pelaku bisnis dalam industri kerajinan gerabah) dan proses bisnis eksternal (penjualan produk kepada konsumen). Proses bisnis internal dilakukan dengan mendata pemilik industri oleh admin melalui website. Sedangkan proses bisnis eksternal dilakukan oleh konsumen dengan melakukan pembelian produk gerabah 
melalui internet. Pembayaran dilakukan dengan mentransfer rekening bank. Setelah konsumen mengkonfirmasi pembayaran produk ditambah dengan biaya pengiriman, pemilik industri melakukan pemaketan produk. Paket ini dikirim oleh jasa pengiriman barang ke alamat konsumen.

\subsection{Pemodelan Sistem dengan UML}

\subsubsection{Use Case Diagram}

Gambar 3 menunjukkan Use Case Diagram yang dapat dilakukan oleh seorang member. Member adalah seorang user di luar anggota UMKM gerabah yang dapat menggunakan sistem. Seorang user yang akan melakukan pemesanan produk diharuskan menjadi member. Member dapat memasukkan data pemesanan produk, memasukkan bukti pembayaran setelah member tersebut melakukan pembayaran terhadap produk yang dipesan. Selain itu, member dapat memasukkan data penerimaan dketika produk yang dipesan telah terkirim.

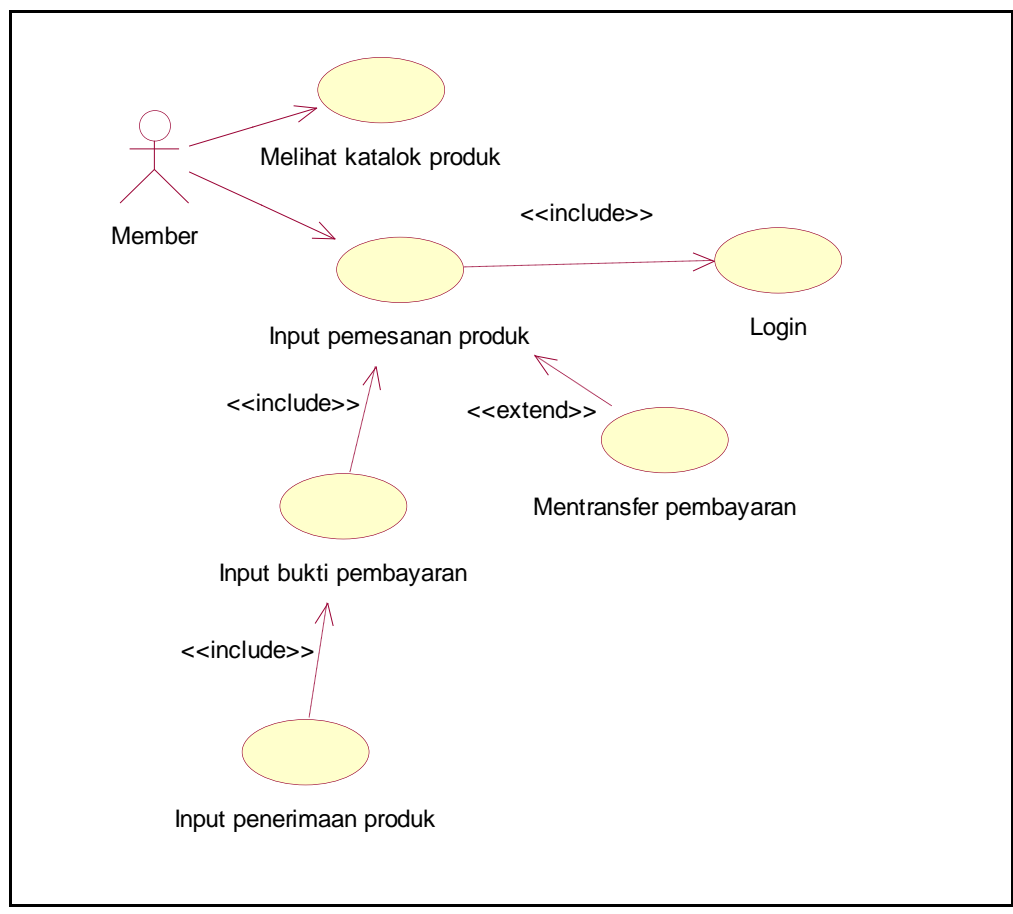

Gambar 3 Use Case Diagram Member

Gambar 4 menunjukkan Use Case Diagram yang dapat dilakukan oleh seorang admin. Admin adalah seorang user yang beraasal dari anggota UMKM gerabah yang dapat menggunakan sistem. Admin dapat melihat data pemesanan produk yang dilakukan oleh member, mengecek ketersediaan produk, melihat data pembayaran, dan menginputkan data pengiriman produk.

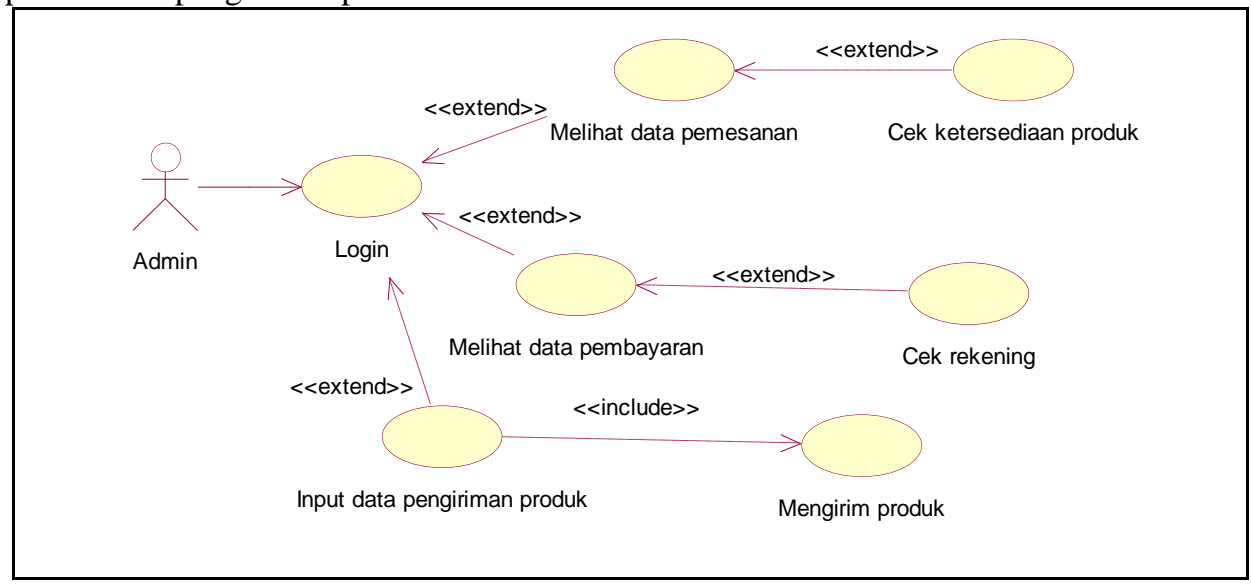

Gambar 4 Use Case DiagramAdmin 


\subsubsection{Statechart Diagram}

Statechart Diagram dari model e-business industri kerajinan gerabah di daerah Mayong ditunjukkan dengan gambar 5 berikut ini:

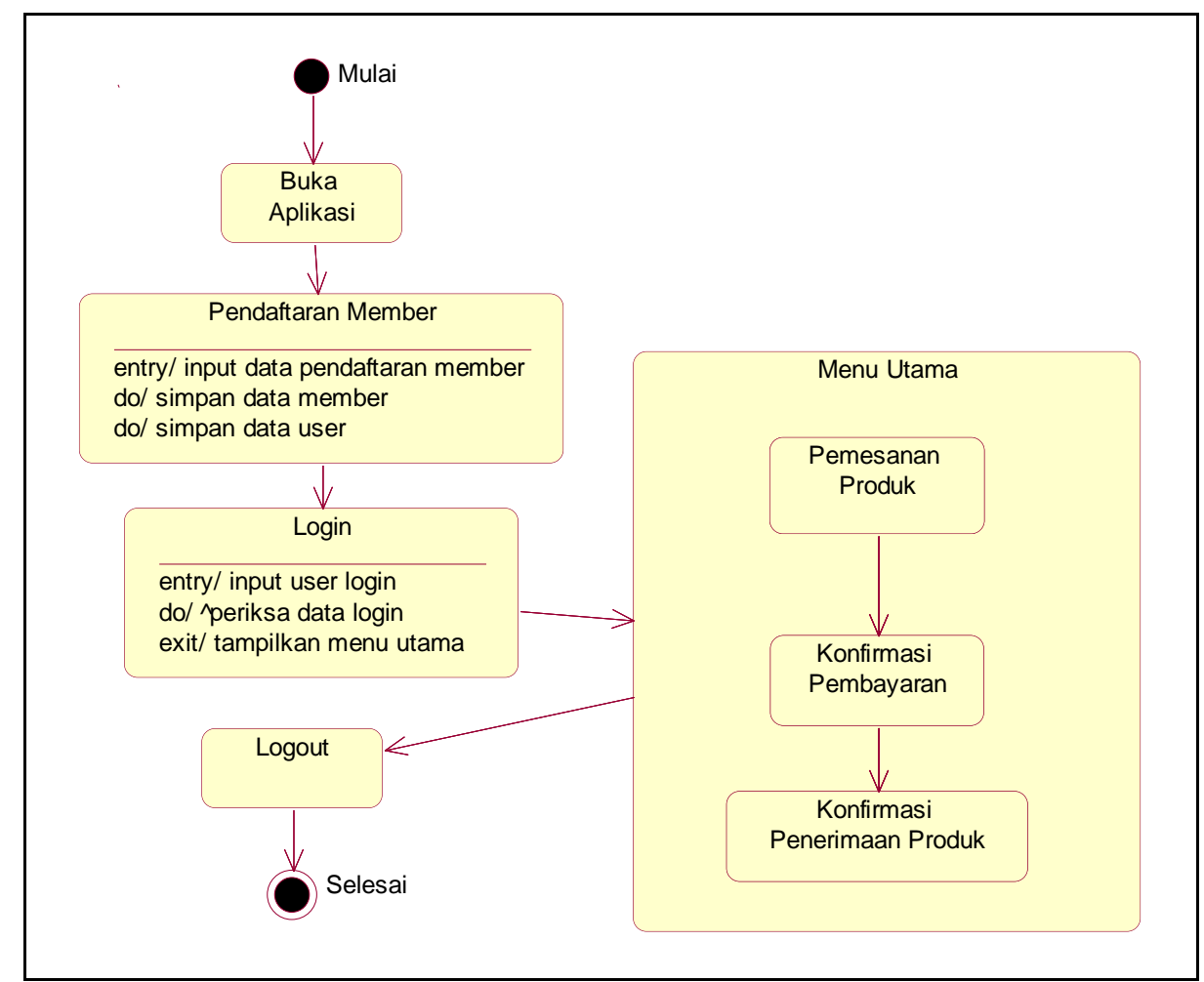

Gambar 5 Statechart Diagram

\subsection{Perancangan Database}

Perancangan database yang diusulkan dalam model e-business industri kerajinan gerabah di daerah Mayong dengan munggunakan DBMS MySQL adalah sebagai berikut:

1. Nama Tabel : user

Fungsi : menyimpan data user

Primery key : UserID

Foreign key :-

Tabel user selengkapnya ditunjukkan pada tabel 1

Tabel 1 Tabel user

\begin{tabular}{lll}
\hline \multicolumn{1}{c}{ Nama Field } & \multicolumn{2}{c}{ Type } \\
\hline UserID & char & 5 \\
Username & varchar & 10 \\
password & varchar & 30 \\
level_user & enum & 'Admin','Member' \\
nama & varchar & 50 \\
jenis_kelamin & enum & 'Laki-laki','Perempuan' \\
alamat & text & \\
telp & varchar & 20 \\
\hline
\end{tabular}


2. Nama Tabel : member

Fungsi : menyimpan data member (customer)

Primery key : IDmember

Foreign key :-

Tabel member selengkapnya ditunjukkan pada tabel 2

Tabel 2 Tabel member

\begin{tabular}{lll}
\hline \multicolumn{1}{c}{ Nama Field } & \multicolumn{1}{c}{ Type } & Size \\
\hline IDmember & char & 5 \\
nama & varchar & 50 \\
jenis_kelamin & enum & 'Laki-laki','Perempuan' \\
pekerjaan & varchar & 30 \\
alamat & text & \\
telp & varchar & 20 \\
\hline
\end{tabular}

3. Nama Tabel : produk

Fungsi : menyimpan data produk

Primery key : IDproduk

Foreign key :-

Tabel produk selengkapnya ditunjukkan pada tabel 3

Tabel 3 Tabel produk

\begin{tabular}{llll}
\hline \multicolumn{1}{c}{ Nama Field } & \multicolumn{2}{c}{ Type } & Size \\
\hline IDproduk & char & 6 \\
nama_produk & varchar & 30 & \\
keterangan & text & \\
harga & int & 10 \\
berat & float & & \\
\hline
\end{tabular}

4. Nama Tabel : transaksi

Fungsi : menyimpan data transaksi

Primery key : IDpesan

Foreign key : IDmember

Tabel transaksi selengkapnya ditunjukkan pada tabel 4

Tabel 4 Tabel transaksi

\begin{tabular}{llll}
\hline \multicolumn{1}{c}{ Nama Field } & \multicolumn{2}{c}{ Type } & Size \\
\hline IDpesan & char & 6 \\
tgl_pesan & date & \\
IDmember & char & 6 \\
total_harga & int & 10 \\
ongkos_kirim & int & 10 \\
tgl_transfer & date & \\
jumlah_transfer & int & 10 \\
no_rekening & varchar & 20 \\
alamat_kirim & text & \\
tgl_terima & date & \\
\hline
\end{tabular}


5. Nama Tabel : item_transaksi

Fungsi : menyimpan item transaksi

Primery key : IDitem

Foreign key : IDpesan, IDproduk

Tabel item_transaksi selengkapnya ditunjukkan pada tabel 5

Tabel 5 Tabel item_transaksi

\begin{tabular}{lll}
\hline \multicolumn{1}{c}{ Nama Field } & \multicolumn{2}{c}{ Type } \\
\hline IDitem & char & 10 \\
IDpesan & char & 6 \\
IDproduk & char & 10 \\
jumlah & int & 'Admin','User','Member' \\
\hline
\end{tabular}

Gambar 6 berikut ini adalah relasi antar tabel dalam industri kerajinan gerabah di daerah Mayong

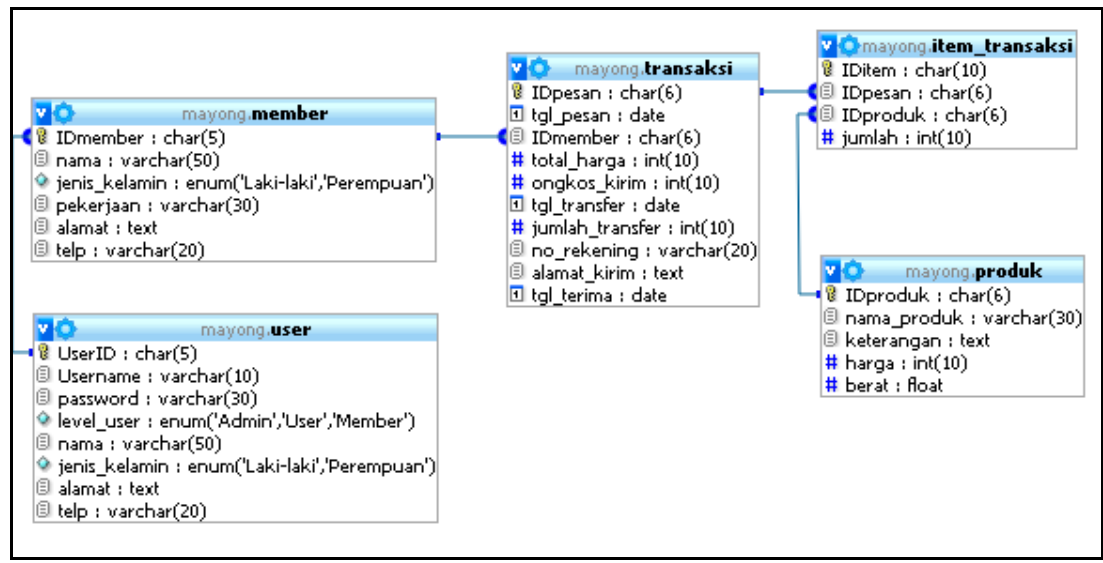

Gambar 6 Relasi antar Tabel

\subsection{Perancangan Interface}

\subsubsection{Form Member}

Desain form member ditunjukkkan pada gambar 7 berikut ini:

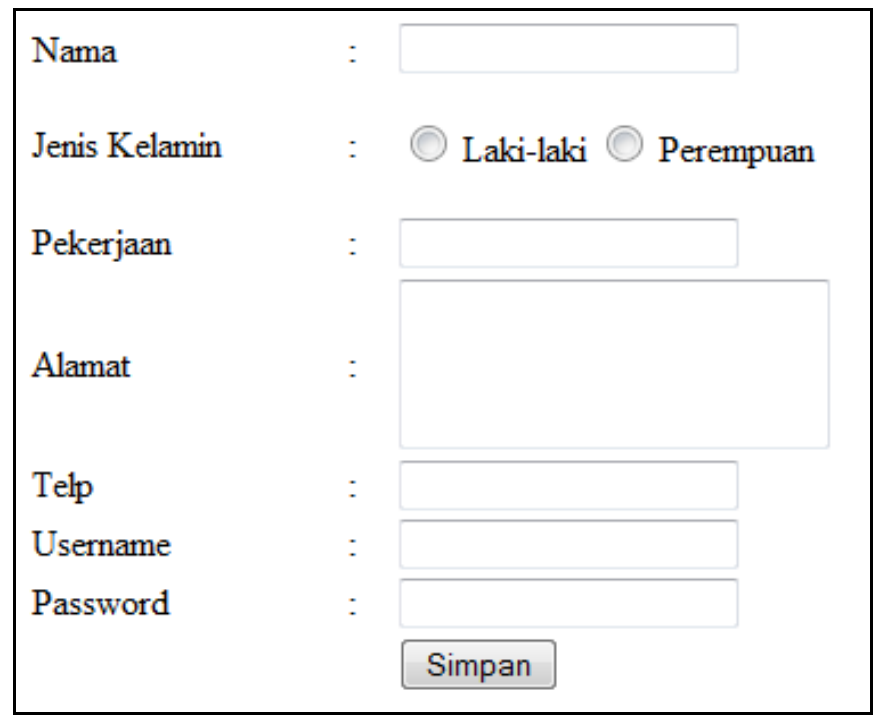

Gambar 7 Form Member 


\subsubsection{Form Pemesanan Produk}

Desain form pemesanan produk ditunjukkkan pada gambar 8 berikut ini:

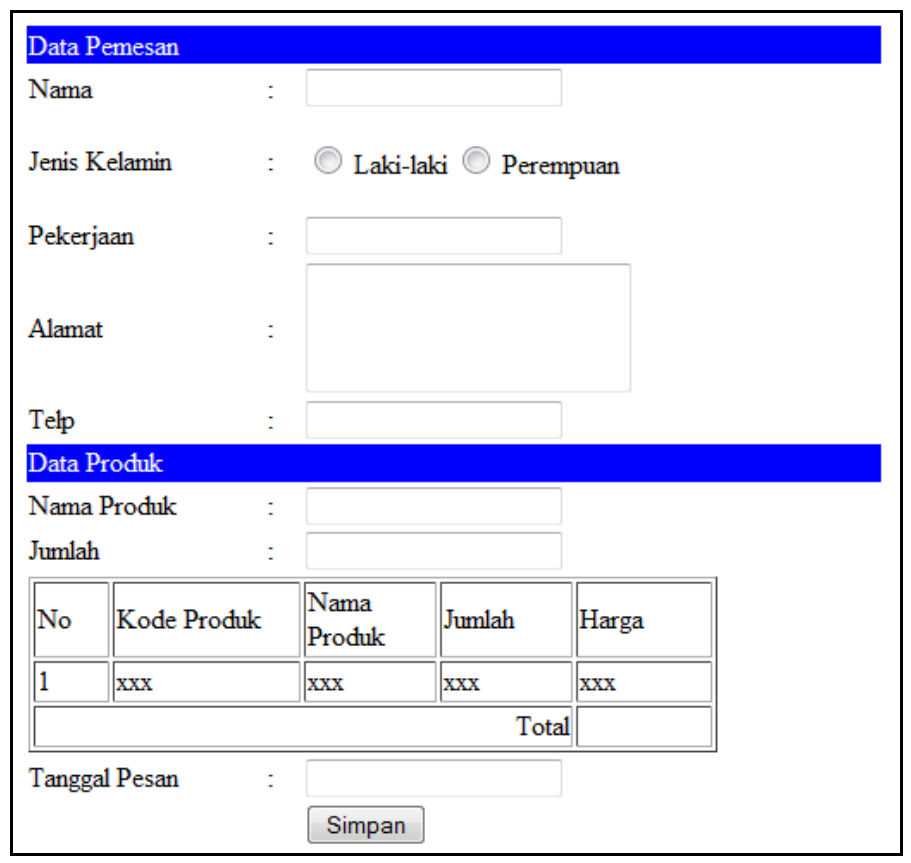

Gambar 8 Form Pemesanan Produk

\subsubsection{Form Konfirmasi Pembayaran}

Desain form konfirmasi pembayaran ditunjukkkan pada gambar 9 berikut ini:

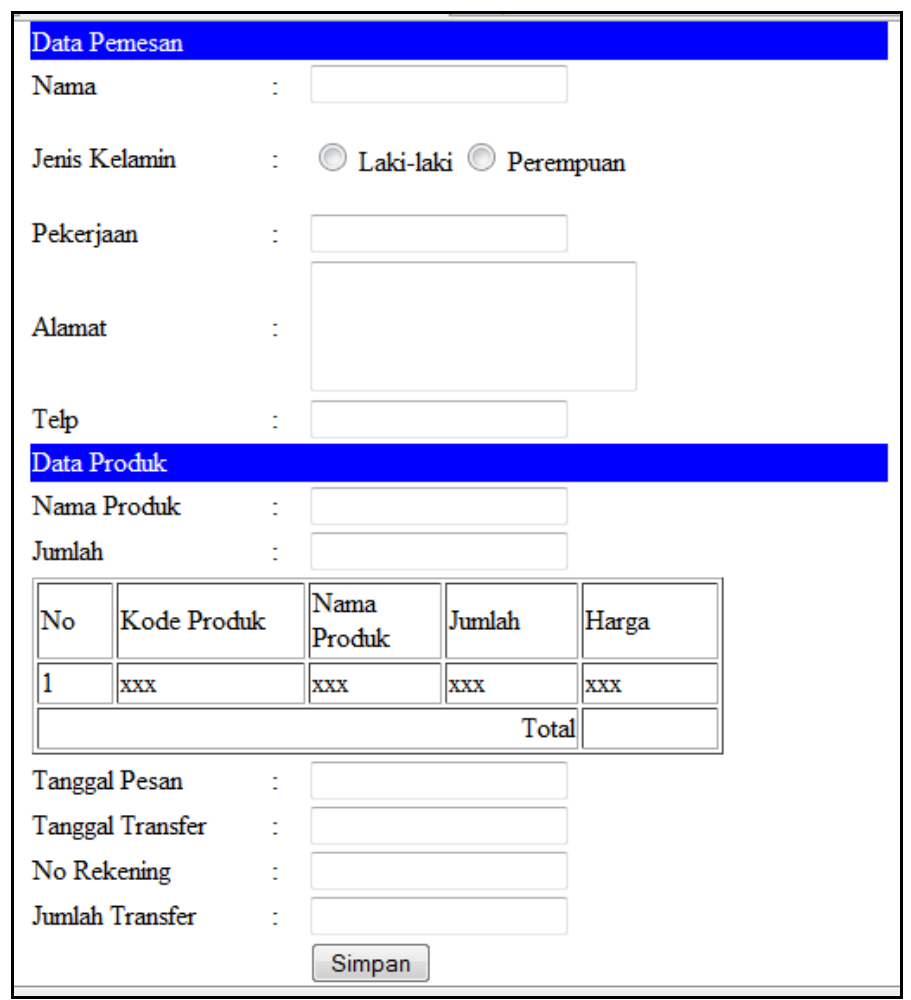

Gambar 9 Form Konfirmasi Pembayaran 
4.5.4 Form Konfirmasi Penerimaan Produk

Desain form konfirmasi penerimaan produk ditunjukkkan pada gambar 10 berikut ini:

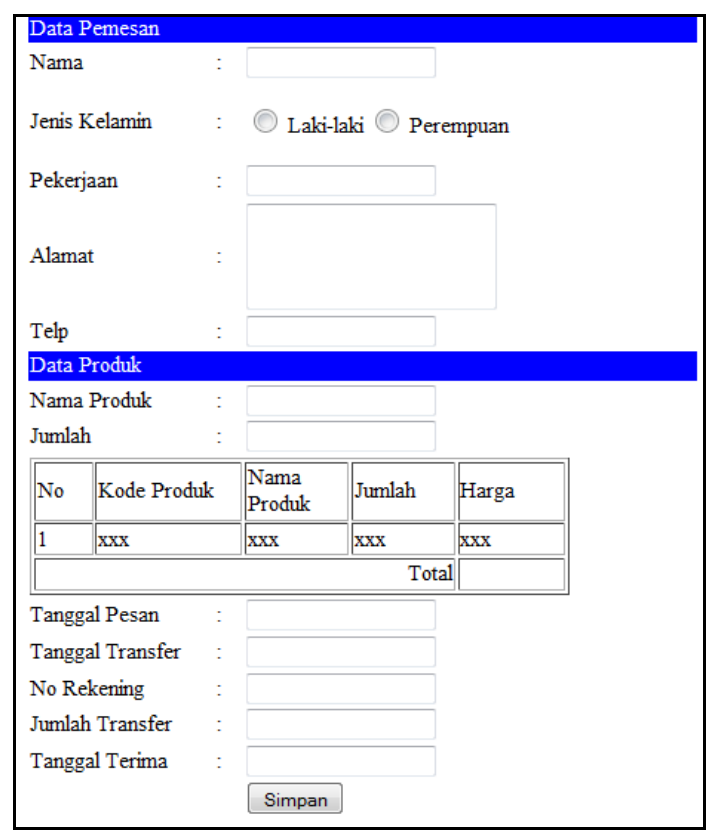

Gambar 10 Form Konfirmasi Penerimaan Produk

\section{KESIMPULAN}

Dari penelitian ini dapat diambil kesimpulan bahwa model e-business dapat digunakan untuk meningkatkan keunggulan kompetitif UMKM gerabah yang ada di daerah Mayong kabupaten Jepara.

\section{DAFTAR PUSTAKA}

[1] Amit, R, C. Zott. (2001). Value Creation in E-Business. Strategic Management Journal. 22. 493-520

[2] Combe, Colin. (2006). Introduction to E-Business Management and Strategy. Netherland: Elsevier

[3] Daft, RL, AY Lewin. (1993). Where are the Theories for the New Organizational Forms? An Editorial Essay. Organization Science. 4(4). i-iv

[4] Departemen Perindustrian. (2009). PERATURAN MENTERI PERINDUSTRIAN REPUBLIK INDONESIA NOMOR 135/M-IND/PER/10/2009 TENTANG PETA PANDUAN (ROAD MAP) PENGEMBANGAN KLASTER INDUSTRI GERABAH DAN KERAMIK HIAS. Jakarta: Departemen Perindustrian.

[5] Dunbar, RLM, WH Starbuck. (2006). Learning to Design Organizations and Learning from Designing Them. Organization Science, 17(2), 171-178

[6] Ellinger, A., Lynch, D., \& Hansen, J. (2003). Firm Sized, We Site Content, and Financial Performance in the Transportation Industry, Industrial Marketing Management, 32, 177-185.

[7] Gefen, D., (2003). TAM or Just Plain Habit: A Look at Experirnced Online Shoppers", Journal of End User Computing, 15(3), 1-13.

[8] Haag, S., Cummings, M., \& Dawkins, J. (1998), Management Information Systems for the Information Age, USA: McGraw-Hill

[9] Ignatius, J. \& Ramayah, T., (2005), “An Empirical Investigation of the Cource Website Acceptance Model (CWAM), International Journal of Business and Society, 6(2), 69-82.

[10] Khotimah, Tutik \& Darsin, (2012). Model E-Business untuk Klaster Industri Kerajinan Gerabah. Proceeding of Conference in Business, Accounting and Management (CBAM), 1(1)

[11] Sellito, C., Wenn, A., \& Burgess, S. (2003). A Review of the Web Sites of Small Australian Wineries: Motivations, Goals and Success, Information Technology and Management, 4(4), 215-232.

[12] Tamimi, N., Sebastianelli, R. \& Rajan, M.(2005). What do online customers value?, Quality Progress, 38(7), 35-39 
[13] Teo, T., \& Pian (2004), A Model for Web Adoption, Information \& Management, 41, 457-468.

[14] Timmers, P. (1999). Electronic Commerce: Strategies and Models for Business-to-Business Trading. Chichester, England: John Wiley and Sons Ltd

[15] Young, D. \& Benamati, J. (2000), Differences in Public Web Sites: The Current State of Large U.S Firms, Journal of E-Commerce Research, 1(3), 94-105, www.csulb.edu/web/journals/jecr/p i.html

[16] Zwass, V ., (1998), Foundation of Information Systems, International Edition, USA: McGraw-Hill 